\title{
Tying different knots in a molecular strand
}

DOI:

10.1038/s41586-020-2614-0

\section{Document Version}

Accepted author manuscript

Link to publication record in Manchester Research Explorer

\section{Citation for published version (APA):}

Leigh, D. A., Schaufelberger, F., Pirvu, L., Stenlid, J. H., August, D. P., \& Segard, J. (2020). Tying different knots in a molecular strand. Nature, 584(7822), 562-568. https://doi.org/10.1038/s41586-020-2614-0

\section{Published in:}

Nature

\section{Citing this paper}

Please note that where the full-text provided on Manchester Research Explorer is the Author Accepted Manuscript or Proof version this may differ from the final Published version. If citing, it is advised that you check and use the publisher's definitive version.

\section{General rights}

Copyright and moral rights for the publications made accessible in the Research Explorer are retained by the authors and/or other copyright owners and it is a condition of accessing publications that users recognise and abide by the legal requirements associated with these rights.

\section{Takedown policy}

If you believe that this document breaches copyright please refer to the University of Manchester's Takedown Procedures [http://man.ac.uk/04Y6Bo] or contact uml.scholarlycommunications@manchester.ac.uk providing relevant details, so we can investigate your claim.

\section{OPEN ACCESS}




\title{
Tying different knots in a molecular strand
}

David A. Leigh ${ }^{1,2 *}$, Fredrik Schaufelberger ${ }^{2,4}$, Lucian Pirvu ${ }^{2,4}$, Joakim Halldin Stenlid ${ }^{3}$, David P. August $^{2}$, Julien Segard ${ }^{2}$

${ }^{1}$ School of Chemistry and Molecular Engineering, East China Normal University, 200062 Shanghai, China.

${ }^{2}$ Department of Chemistry, University of Manchester, Oxford Road, Manchester, M13 9PL, UK.

${ }^{3}$ Department of Physics, AlbaNova University Center, Stockholm University, S-10691 Stockholm, Sweden.

${ }^{4}$ These authors contributed equally: Lucian Pirvu, Fredrik Schaufelberger.

*e-mail: david.leigh@manchester.ac.uk

\section{Keywords:}

Molecular knots, supramolecular chemistry, coordination chemistry, knot theory, molecular folding, topology

\begin{abstract}
A piece of rope or cord can be tied into different knots with their, often contrasting, properties exploited in a range of applications, from shoelaces to the knots used for climbing, fishing and sailing. ${ }^{1}$ Although knots are found in DNA and proteins, ${ }^{2}$ and form randomly in other long polymer chains, ${ }^{3,4}$ there is currently a lack of methods for tying ${ }^{5}$ different sorts of knots in a synthetic nanoscale strand. Here we show that interspersing coordination sites for different metal ions within an artificial molecular strand enables it to be tied into multiple knots. Three topoisomers-an unknot $\left(0_{1}\right)$ macrocycle, a trefoil $\left(3_{1}\right)$ knot, ${ }^{6-15}$ and a three-twist $\left(5_{2}\right)$ knot-were each selectively prepared from the same molecular strand by using transition metal and lanthanide ions to guide chain folding in a manner reminiscent of the role played by protein chaperones. ${ }^{16}$ We find that the metal-ion-induced folding can proceed with stereoinduction: for one knot a lanthanide(III)-coordinated crossing pattern only formed with a copper(I)coordinated crossing of particular handedness. In an unanticipated finding, metal ion coordination was also found to be able to translocate an entanglement from one region of a knotted molecular structure to another, resulting in an increase in writhe (topological strain) in the new knotted conformation. The knot topology affects the chemical properties of the strand: while the tighter $5_{2}$ knot can bind two, different, metal ions simultaneously, the looser $3_{1}$ isomer can only bind either one $\mathrm{Cu}(\mathrm{I})$ ion or one $\mathrm{Lu}(\mathrm{III})$ ion. The ability to tie nanoscale chains into different knots offers new opportunities to explore for modifying the structure and properties of synthetic oligomers, polymers and supramolecules.
\end{abstract}

\section{Main}

The way that strand crossing patterns define knot topoisomerism ${ }^{17}$ is reminiscent of the stereochemical relationship between asymmetric centers in conventional organic molecules ${ }^{18}$. As the handedness of existing asymmetric centres can influence that of new stereocenters formed in chemical reactions,${ }^{19}$ we wondered if a similar approach could be used to control topology in chemical synthesis, i.e. whether the stereochemistry of some strand crossings could determine the crossing orientation of others? This could allow access to molecular knots of low symmetry; a contemporary challenge for knot synthesis as the topologies prepared to date have generally relied on high symmetry self-assembly ${ }^{20}$ of multiple building blocks ${ }^{6-8,11-14,21-24}$. Nature folds peptide chains to reach discrete 3D structures, including knots, ${ }^{2,25,26}$ often through the assistance of chaperones that guide folding to a particular conformation through the myriad of possible pathways. Chaperones accelerate the knotting of methyltransferases by several orders of magnitude ${ }^{27}$ and promote the formation of the $5_{2}$-twist knot of human protein ubiquitin hydrolase ${ }^{28,29}$. We investigated the use of metal ion coordination in a conceptually similar manner, to fold $^{30-32}$ a synthetic molecular strand into particular, well-defined, ${ }^{33}$ entanglements (Fig. 1a). We envisaged that the crossing stereochemistry could then be covalently captured by ring-closing olefin metathesis $^{34}$ (RCM) to form the corresponding closed-loop topologies, such as a three-twist $\left(5_{2}\right) \mathrm{knot}$ (Fig. 1b). The latter is a low symmetry topology found in DNA and proteins, ${ }^{2}$ but inaccessible using current synthetic chemistry strategies ${ }^{35,36}$.

The strategy we devised to tie a molecular thread into different knots is to intersperse 'guest-orthogonal' binding sites within the strand such that various discrete 'tangles'17,36,37 (simple crossing patterns that can be combined to form knots $^{38}$ ) are formed by activating some, all or none of the different binding 
sites in the strand. This produces a metallofoldamer ${ }^{32}$ that can be programed to fold selectively into any one of several differently knotted intermediates. Pentatopic ligand strand L1 (Fig. 1b) features two kinds of metal complexation sites: (i) bidentate 1,10-diphenylphenanthroline (dpp) units, two of which bind to $\mathrm{Cu}(\mathrm{I})$ ions in a tetrahedral coordination geometry, ${ }^{6,39}$ and (ii) tridentate 2,6-pyridine dicarboxamide (pdc) groups, three of which coordinate to trivalent lanthanide cations to form a trimeric circular helicate ${ }^{40}$. By alternating the binding sites in the sequence pdc-dpp-pdc-dpp-pdc, higher order entanglements can be introduced through stepwise folding and threading of the strand ends through an intermediate containing an internal loop (Fig. 1a). The lanthanide trimeric helicate is forced to be of $\Lambda$-helicity because of the steric requirements of $(R)$-stereocentres adjacent to the pdc groups. ${ }^{41,42}$ The chirality enforced in those crossings can be used to select the stereochemistry of the Cu-coordinated loop (Fig. 1c), a process analogous to using existing chirality to control the stereochemistry of new asymmetric centres in conventional stereoselective synthesis ${ }^{19}$.

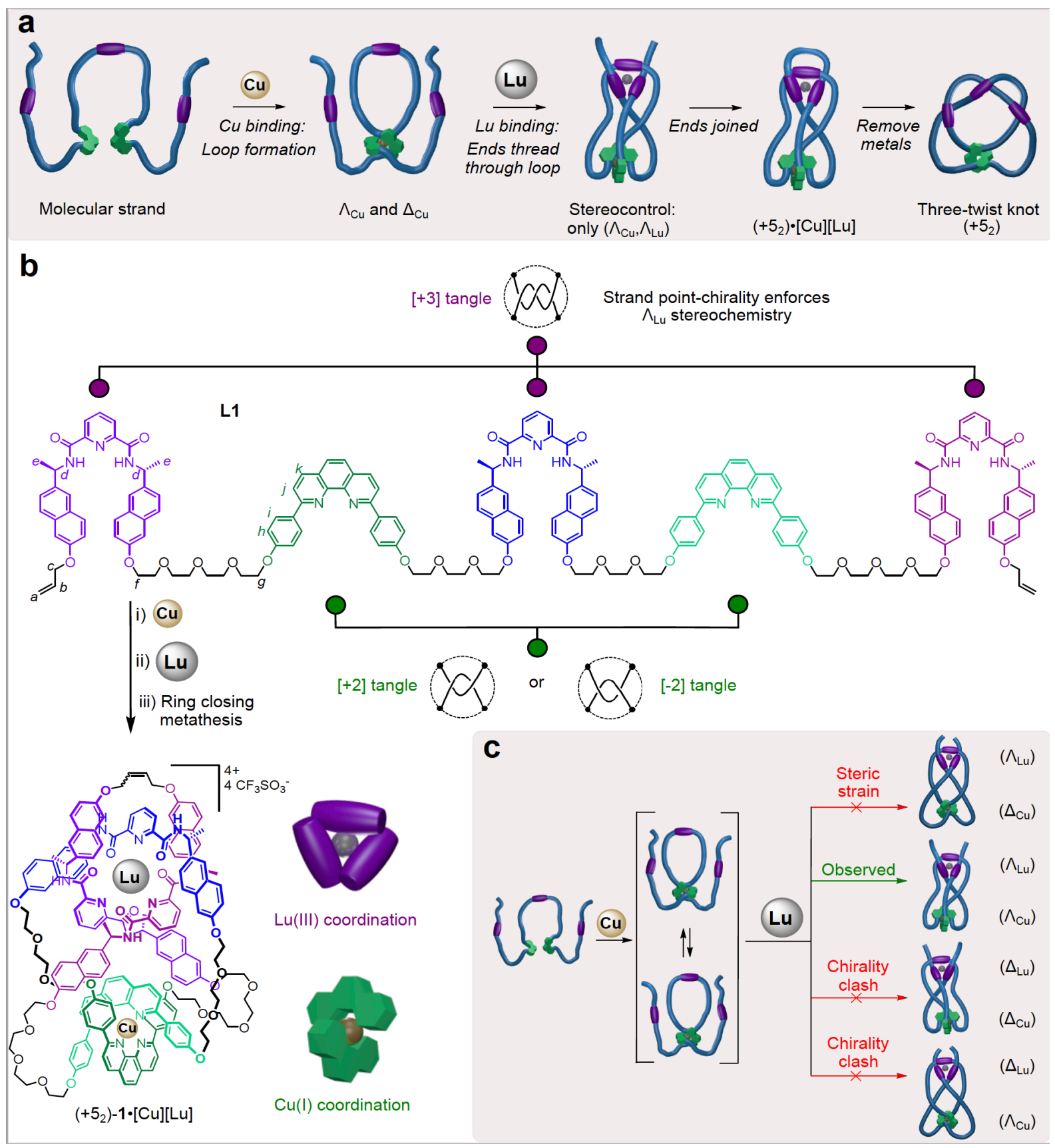

Figure 1. Tying molecular strand L1 into a three-twist $\left(5_{2}\right)$ knot through metal-ion-induced folding and entanglement. a) Stepwise folding, threading and covalent-capture of a pentatopic ligand with interspersed metal binding sites. b) Ligand L1 contains three 2,6-pyridine dicarboxamide (pdc) sites (purple/blue) which code for the enantioselective formation of a [+3] tangle under $\operatorname{Ln}(\mathrm{III})$ coordination, and two 1,10-diphenylphenanthroline (dpp) 
sites (green) which code for a [+2] or [-2] tangle upon $\mathrm{Cu}(\mathrm{I})$ coordination. A three-twist $\left(5_{2}\right)$ knot is tied through stepwise metal ion addition $(\mathrm{Cu}(\mathrm{I})$ then $\mathrm{Lu}(\mathrm{III}))$ and subsequent macrocyclization via ring-closing olefin metathesis. Reaction conditions: (i) $\left(\mathrm{Cu}\left(\mathrm{CF}_{3} \mathrm{SO}_{3}\right)\right)_{2}$ toluene, $\mathrm{MeCN} / \mathrm{CH}_{2} \mathrm{Cl}_{2} 1: 2,50{ }^{\circ} \mathrm{C}, 16 \mathrm{~h}, 93 \%$. (ii) $\mathrm{Lu}\left(\mathrm{CF}_{3} \mathrm{SO}_{3}\right)_{3}, \mathrm{MeCN}, 80$ ${ }^{\circ} \mathrm{C}, 16 \mathrm{~h}$. (iii) Hoveyda-Grubbs 2 nd Generation catalyst, $\mathrm{CH}_{3} \mathrm{NO}_{2} / \mathrm{CH}_{2} \mathrm{Cl}_{2} 1: 1,50{ }^{\circ} \mathrm{C}, 20 \mathrm{~h}, 14 \%$ over two steps. For full experimental details, including synthesis of L1, see Supplementary Information. Letter annotation in chemical structure refers to general proton environments. c) Outcomes that could occur without control of crossing stereochemistry. Only $\Lambda$-stereochemistry at both the $\operatorname{Ln}(\mathrm{III})$ and $\mathrm{Cu}(\mathrm{I})$ centres is observed for the experimentally synthesized molecular $55_{2}$-knot. Regarding the nomenclature used in this paper: $\Lambda$ - and $\Delta$ - (e.g. $\Lambda_{\text {Lu }}$ ) are standard descriptors for the helicity around metal centres and indicate the coordination stereochemistry at metal centers in the open-ended strand, L1. For closed-loop structures, $\left(+X_{y}\right)$ and $\left(-X_{y}\right)$ are Alexander-Briggs notation ${ }^{17,36}$ for the enantiomers of a knot with $X$ crossings and $y$ index number (i.e. a particular pattern of $X$ crossings). So ' $\left(+5_{2}\right)$ $1 \cdot[\mathrm{Cu}][\mathrm{Lu}]$ ' indicates a copper(I) and lutetium(III) coordination complex of the (+)-enantiomer of the $5_{2}$-topology of chemical structure 1.

\section{Tying a $\mathbf{5}_{2}$ knot in a molecular strand}

Combining ligand $\mathrm{L1}$ (Fig. $1 \mathrm{~b}$ ) with $\left[\mathrm{Cu}\left(\mathrm{CF}_{3} \mathrm{SO}_{3}\right)\right]_{2}{ }^{\circ}$ toluene in $\mathrm{MeCN} / \mathrm{CHCl}_{3}$ at $50^{\circ} \mathrm{C}$, smoothly generated L1. $\left[\mathrm{Cu}\right.$ ], as evidenced by mass spectrometry and ${ }^{1} \mathrm{H}$ NMR chemical shifts (see for example $\mathrm{H}_{\mathrm{i}}$ and $\mathrm{H}_{\mathrm{h}}$, Fig. 2a and b, and the Supplementary Information section S7). There is no induced circular dichroism in the phenanthroline region (see Fig. 2d and Supplementary Fig. S73-S74) indicating that the $\mathrm{Cu}(\mathrm{I})$ coordinated crossing forms without stereocontrol (a [ \pm 2$]$ tangle; Fig. 1c). The central pdc unit of the strand is within the closed loop of $\mathrm{L1} \cdot[\mathrm{Cu}]$. As the strand ends are positioned on opposite faces of the $\mathrm{L} 1 \cdot[\mathrm{Cu}]$ loop, coordination of a lanthanide ion to the three pdc residues to form the circular helicate motif requires the strand to thread through the loop from different sides. The length of the spacers between the pdc and dpp groups were chosen using molecular modelling (see Supplementary Information section S6.5), such that $\Lambda$-handedness of the $\mathrm{Cu}(\mathrm{I})$-coordinated loop allows the strand ends to thread through the loop more easily to form the $\Lambda$-helical $\mathrm{Lu}(\mathrm{III})$-coordination complex.

Treating complex $\mathrm{L} 1 \cdot[\mathrm{Cu}]$ with $\mathrm{Lu}(\mathrm{OTf})_{3}$ in $\mathrm{MeCN}$, followed by covalent capture through ring closing olefin metathesis, ${ }^{34}$ afforded predominantly one major species, $1 \cdot[\mathrm{Cu}][\mathrm{Lu}]$, as indicated by mass spectrometry and ${ }^{1} \mathrm{H}$ NMR spectroscopy. The bimetallic structure was isolated as $1 \cdot[\mathrm{Cu}]\left[\mathrm{Lu}_{[}\left[\mathrm{CF}_{3} \mathrm{SO}_{3}\right]_{4}\right.$ after purification by exhaustive size-exclusion chromatography (SEC) in 13\% yield over 3 steps from L1 (the yield for the isolated material is low in part because of the difficulty in separating the product from the small amounts of other, likely misfolded, species also formed). Electrospray ionization mass spectrometry (ESI-MS) was consistent with a ring-closed [Cu][Lu] complex (Figs. S14-S16, m/z

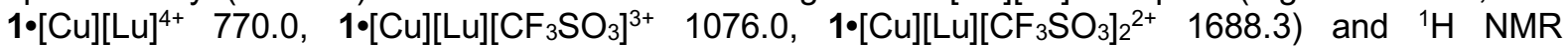
spectroscopy confirmed the entangled structure of the knot (Fig. 2c, Figs. S27 and S28). Among the spectral changes that occur upon knotting, protons $\mathrm{Hh}_{\mathrm{h}}$ of the phenanthroline rings shift upfield from a single signal at $7.0 \mathrm{ppm}$ in the metal-free strand, L1 (Fig. 2a), into four distinct signals at 5.6-6.1 ppm in bimetallic complex 1•[Cu][Lu] (Fig. 2c), indicative of $\mathrm{Cu}(\mathrm{I})$ binding to the dpp units to form a clasp crossing, and pronounced diastereotopic environments caused by the chiral lanthanide-coordinated tangle (similar effects observed for $\mathrm{H}_{k}, \mathrm{H}_{\mathrm{j}}, \mathrm{H}_{\mathrm{i}}$ and $\mathrm{H}_{\mathrm{d}}$ ). Several of the methyl groups $\left(\mathrm{H}_{\mathrm{e}}\right)$ undergo upfield shifts, reflecting their shielded positions in the folded structure (Fig. S13). Diffusion-Ordered Nuclear Magnetic Resonance Spectroscopy (DOSY-NMR) confirmed the complex to be a single species (Fig. S39), smaller in size than the corresponding unknot macrocycle, $\left(0_{1}\right)-1$ (Fig. S34, Table S2), and consistent with an energy-minimized modelled structure of the compact, entangled, structure of the $5_{2}$ knot (Figs. 2e and f). 

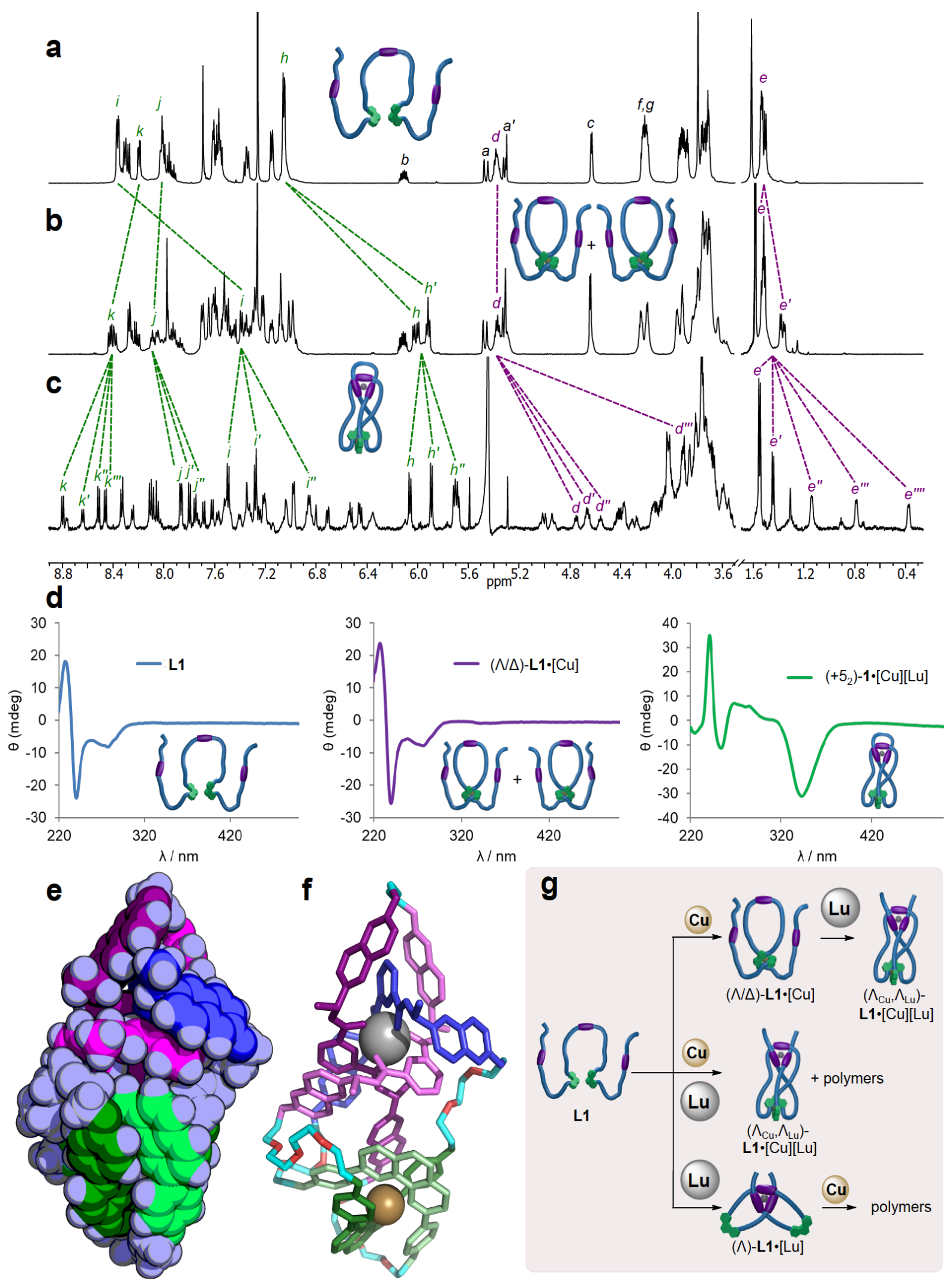

Figure 2. Spectroscopic characterisation and modelled structure of molecular knot $\left.\left(+5_{2}\right)-1 \cdot[\mathrm{Cu}][\mathrm{Lu}] \cdot \mathrm{a}-\mathrm{C}\right)^{1} \mathrm{H}$ NMR spectra $(600 \mathrm{MHz})$ of the three-twist knot tying process: a) ligand L1 $\left(298 \mathrm{~K}, \mathrm{CDCl}_{3}\right)$; b) $\mathrm{Cu}(\mathrm{I})$-coordinated complex L1•[Cu] $\left(298 \mathrm{~K}, \mathrm{CDCl}_{3}\right)$; c) bimetallic three-twist knot $\left(+5_{2}\right)-1 \cdot[\mathrm{Cu}][\mathrm{Lu}]\left(343 \mathrm{~K}, \mathrm{MeCN}-d_{3}\right)$. Key proton resonances are designated with the lettering indicated in Fig. 1b. Primes following letters are used to indicate that previously indistinguishable chemical environments no longer appear equivalent due to the more strongly expressed diastereotopic environments in the chiral knot structure. For full structural assignments see Supplementary Information. d) CD spectra $(298 \mathrm{~K})$ after key steps in the strand-folding process. Compounds L1 and $\mathrm{L1} \cdot[\mathrm{Cu}]$ measured in $\mathrm{CH}_{2} \mathrm{Cl}_{2}(0.025 \mathrm{mM})$ and $\left(+5_{2}\right)-1 \cdot[\mathrm{Cu}][\mathrm{Lu}]$ in $\mathrm{MeCN}(0.1 \mathrm{mM})$. e) Optimized low- 
energy geometry (B3LYP-D3/6-311 $\mathrm{g}(\mathrm{d}, \mathrm{p}) / / 6-31 \mathrm{~g}(\mathrm{~d})$ with the RECP basis set for Lu, see Supplementary Information for details) of the three-twist knot, $\left(+5_{2}\right)-1 \cdot[\mathrm{Cu}][\mathrm{Lu}]$, in space-filling representation. f) Corresponding stick representation of $\left(+5_{2}\right)-1 \cdot[\mathrm{Cu}][\mathrm{Lu}]$ (hydrogens omitted for clarity). g) Folding pathway dependence on the sequence of metal ion addition (see Supplementary Information, section S5.2).

As the asymmetric carbon atoms adjacent to the pdc units force the Lu(III)-(pdc) 3 tangle to have $\Lambda$ stereochemistry, ${ }^{38}$ the stereochemistry of the $\mathrm{Cu}(\mathrm{I})-(\mathrm{dpp})_{2}$ clasp crossing determines the knot topology. The pronounced CD response in the $\pi-\pi^{*}$ transitions of the phenanthroline chromophore (Fig. 2d, right) results from one handedness of the $\mathrm{Cu}(\mathrm{l})$-coordinated centre being preferentially selected during the threading step. Literature precedence ${ }^{43}$ for chiral $\mathrm{Cu}(\mathrm{I})-(\mathrm{dpp})_{2}$ junctions is that a negative Cotton effect at $330 \mathrm{~nm}$ corresponds to $\Lambda$-handedness of the clasp crossing. This means that the topology and stereochemistry of the product is $\left(+5_{2}\right)-1 \cdot[\mathrm{Cu}][\mathrm{Lu}]$. A strong chiral response for the phenanthroline groups is present for the crude reaction mixture following ring-closing olefin metathesis, indicating that the folding proceeds with a significant degree of selectivity for a specific topoisomer (Fig S5). Hence, the stereoselectivity in this region does not arise during the purification process. Rather topological stereoinduction, in the form of a chiral tangle selecting the handedness of a racemic one, occurs during the second metal-induced strand folding step. This results in a single enantiomer ( $\Lambda$-handedness at the $\mathrm{Cu}(\mathrm{I})$ centre) of a single knot topoisomer (52), in an analogous manner to diastereoselective synthesis in conventional organic chemistry. The energy-minimized structure of $\left(+5_{2}\right)-1 \cdot[\mathrm{Cu}][\mathrm{Lu}]$ (Fig. $2 \mathrm{e}$ and $2 \mathrm{f}$ ), obtained by simulated annealing with semi-empirical PM7 modelling, followed by optimization by density functional theory (DFT) calculations, confirmed the spectroscopic and stereochemical assignment of the experimentally prepared knot (see Supplementary Information, section S6). The simulated circular dichroism spectrum of $(+52)-1 \cdot[\mathrm{Cu}][\mathrm{Lu}]$ reproduced the experimental $\mathrm{CD}$ data, including correct prediction of the handedness of the Cu-clasp crossing in the phenanthroline region and the helicity of the Lu-circular helicate (Fig. S12).

\section{Folding pathway for the $\mathbf{5}_{2}$ knot}

The folding to the 52 knot was found not to be under thermodynamic control, as adding the metal ions in different sequences produced different outcomes (Figs. $2 \mathrm{~g}$ and S6, S7). Adding Lu(III) to L1 generated $\left(\Lambda_{\mathrm{Lu}}\right)-\mathrm{L} 1 \cdot[\mathrm{Lu}]$ (Fig. 2g, lower pathway), to which subsequent addition of $\mathrm{Cu}(\mathrm{I})$ salts led to a red precipitate that could not be redissolved, presumably a mixture of $\mathrm{Cu}(\mathrm{I})$-coordinated oligomers and polymers. Adding both $\mathrm{Cu}(\mathrm{I})$ and $\mathrm{Lu}(\mathrm{III})$ salts simultaneously to $\mathbf{L 1}$ (Fig. $2 \mathrm{~g}$, middle pathway) produced some red precipitate together with a modest amount of $\left(\wedge_{\mathrm{Cu}}, \Lambda_{\mathrm{Lu}}\right)-\mathrm{L} 1 \cdot[\mathrm{Lu}][\mathrm{Cu}]$, the fully folded precursor to the 52 knot. Only stepwise addition of first $\mathrm{Cu}(\mathrm{I})$, then $\mathrm{Lu}(\mathrm{III})$ (Fig. $2 \mathrm{~g}$, top pathway), afforded ( $\left.\wedge_{\mathrm{Cu},}, \wedge_{\mathrm{Lu}}\right)-$ $\mathrm{L1} \cdot[\mathrm{Lu}][\mathrm{Cu}]$ as the major, correctly folded, intermediate that could subsequently be covalently captured by RCM to form the 52 knot.

\section{3, knot synthesis and tangle migration}

Strand L1 could be tied into a different knot by simply omitting the $\mathrm{Cu}(\mathrm{I})$-coordination step (Fig. 3a). The strand ends of $\left(\Lambda_{\mathrm{Lu}}\right)-\mathrm{L} \mathbf{1} \cdot[\mathrm{Lu}]$ were subsequently joined by ring closing olefin metathesis (Fig. 3a, step ii). After several rounds of SEC, trefoil knot $\left(-3_{1}\right)-1 \cdot[\mathrm{Lu}]$ was isolated in $60 \%$ overall yield from L1. DOSYNMR confirmed the new knot to be a single molecular species (Fig. S37), mass spectrometry showed its molecular mass to be that of 1•[Lu] (Fig. S17-S19, $\mathrm{m} / \mathrm{z} 1 \cdot[\mathrm{Lu}]^{3+} 1005.6,1 \cdot\left[\mathrm{Lu}^{3}\left[\mathrm{CF}_{3} \mathrm{SO}_{3}\right]^{2+} 1582.5\right.$ ), and CD spectroscopy indicated helically chiral pdc groups coordinated to Lu(III) (Fig. 3b, blue trace). The ${ }^{1} \mathrm{H}$ NMR spectrum of $\left(-3_{1}\right)-1 \cdot[\mathrm{Lu}]$ in $\mathrm{MeCN}-d_{3}$ is broad at room temperature (Fig. S26) but sharpens at $343 \mathrm{~K}$ (Fig. 3c, top trace), revealing proton chemical shifts (e.g. $\mathrm{H}_{\mathrm{d}}$ and $\mathrm{H}_{\mathrm{e}}$ ) indicative of the strand crossings being located in the region of the $\mathrm{Lu}(\mathrm{pdc})_{3}$ coordination motif. 


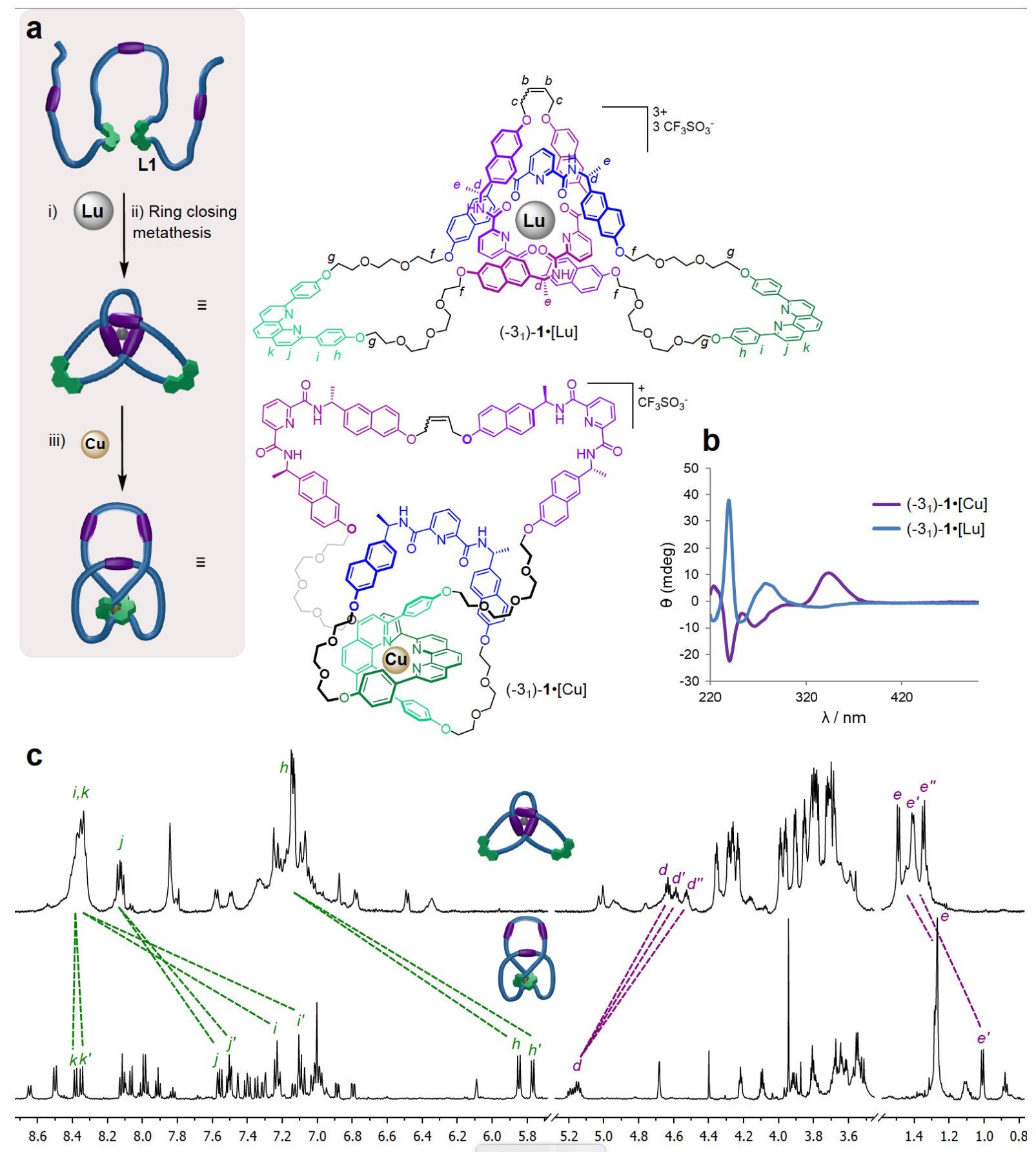

Figure 3. Tying molecular strand L1 into a trefoil $\left(3_{1}\right)$ knot. a) Synthesis of molecular trefoil knot $\left(-3_{1}\right)-1 \cdot[\mathrm{Lu}]$ from ligand $\mathrm{L} 1$ and subsequent entanglement transposition by displacement of $\mathrm{Lu}(\mathrm{III})$ with $\mathrm{Cu}(\mathrm{I})$. Reaction conditions: (i) $\mathrm{Lu}\left(\mathrm{CF}_{3} \mathrm{SO}_{3}\right)_{3}, \mathrm{MeCN}, 80^{\circ} \mathrm{C}, 16 \mathrm{~h}$. (ii) Hoveyda-Grubbs 2 nd Generation catalyst, $\mathrm{CH}_{3} \mathrm{NO}_{2} / \mathrm{CH}_{2} \mathrm{Cl}_{2} 1: 1$, $50{ }^{\circ} \mathrm{C}, 40 \mathrm{~h}, 60 \%$ over two steps. (iii) $\left(\mathrm{CH}_{3} \mathrm{CN}\right)_{4} \mathrm{Cu}\left(\mathrm{CF}_{3} \mathrm{SO}_{3}\right), \mathrm{MeCN}, \mathrm{RT}, 10 \mathrm{~min}, 15 \%$ (after SEC purification). b) CD spectra (MeCN, $0.1 \mathrm{mM}, 298 \mathrm{~K}$ ) of the two knot conformers $\left(-3_{1}\right)-1 \cdot[\mathrm{Lu}]$ (blue) and $\left(-3_{1}\right)-1 \cdot[\mathrm{Cu}]\left(\right.$ purple). c) ${ }^{1} \mathrm{H}$ NMR spectra $\left(600 \mathrm{MHz}, \mathrm{MeCN}-d_{3}, 343 \mathrm{~K}\right)$ of the entanglement transposition from $\left(-3_{1}\right)-1 \cdot[\mathrm{Lu}]$ to $\left(-3_{1}\right)-1 \cdot[\mathrm{Cu}]$. Key ${ }^{1} \mathrm{H}$ signals highlighted, lines indicate changes following addition of $\mathrm{Cu}(\mathrm{I})$ to $\left(-3_{1}\right)-1 \cdot[\mathrm{Lu}]$. For full assignments, see Supplementary information.

When investigating whether lutetium-coordinated trefoil knot $\left(-3_{1}\right)-1 \cdot[\mathrm{Lu}]$ could still bind to an additional $\mathrm{Cu}(\mathrm{I})$ ion through the free dpp binding sites, a surprising result was obtained (Fig. 3a, step iii and Fig. $3 c$, bottom trace). Within five minutes of adding $\mathrm{Cu}(\mathrm{OTf}) \cdot 4 \mathrm{MeCN}$ to a solution of $\left(-3_{1}\right)-1 \cdot[\mathrm{Lu}]$ in $\mathrm{MeCN}$ at room temperature, the solution turned dark red. However, instead of a bimetallic complex, ESI-MS showed that only a single metal ion was bound by the trefoil knot (Figs. S20-S21, m/z 1•[Cu] 2905.1); a $\mathrm{Cu}(\mathrm{I})$ ion had displaced the $\mathrm{Lu}(\mathrm{III})$ ion. An identical species could be prepared step-wise by first 
demetallating $\left(-3_{1}\right)-1 \cdot[\mathrm{Lu}]$ with tetraethylammonium fluoride $\left(\mathrm{Et}_{4} \mathrm{NF}\right)$ in $\mathrm{MeCN}$ and then remetallating with $\mathrm{Cu}(\mathrm{OTf}) \cdot 4 \mathrm{MeCN}$ (see Supplementary Information, section S7). The ${ }^{1} \mathrm{H}$ NMR spectrum of the resulting complex, $\left(-3_{1}\right)-1 \cdot[\mathrm{Cu}]$, shows the metal ion to be coordinated to the dpp sites with the pdc sites vacant (Fig. 3c, bottom trace). The CD spectrum for $\left(-3_{1}\right)-1 \cdot[\mathrm{Cu}]$ shows a strong Cotton effect at 330 $\mathrm{nm}$ (Fig. 3b, purple trace), but unlike $\left(+5_{2}\right)-1 \cdot[\mathrm{Cu}][\mathrm{Lu}]$ this Cotton effect is positive. This corresponds to transfer of the $\Lambda$-helicity from the $\mathrm{Lu}(\mathrm{pdc})_{3}$ tangle to the new clasp crossing site through an additional twist and shift in the position of entanglement within the trefoil knotted chain (Fig. 3a, step iii). This transposition results in an increase in topological writhe from 3 in $\left.\left(-3_{1}\right)-1 \cdot[\mathrm{Lu}]\right)$ to 4 (in $\left.\left(-3_{1}\right)-1 \cdot[\mathrm{Cu}]\right)$. In topological terms ${ }^{17,36}$ the additional nugatory crossing can be introduced via a Reidemeister I+III sequence (Fig. S4). Circular dichroism (Fig. S9) showed that $\mathrm{Cu}(\mathrm{I})$ coordination to the isomeric unknot macrocycle $\left(0_{1}-1\right)$ proceeds without chiral induction in the phenanthroline region, demonstrating that the transfer of handedness to the dpp sites in $\left(-3_{1}\right)-1 \cdot[\mathrm{Cu}]$ is a consequence of the chiral trefoil knot topology, rather than a reflection of the asymmetric centers adjacent to the pdc groups in the strand. The transfer of the location of entanglement from one well-defined region of a knot to another opens up the intriguing possibility of using metal ions, or other stimuli, to manipulate the conformation and writhe of knotted loops in a form of molecular 'cat's cradle"44.

a

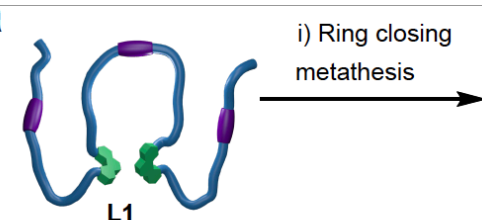

L1

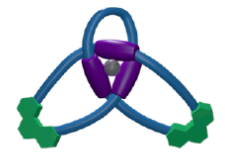

$\left(-3_{1}\right)-1 \cdot[L u]$

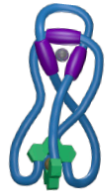

$\left(+5_{2}\right)-1 \cdot[\mathrm{Cu}][\mathrm{Lu}]$

ii) Remove Lu

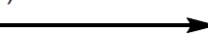

iii) Remove $\mathrm{Lu}$ and $\mathrm{Cu}$

b

b

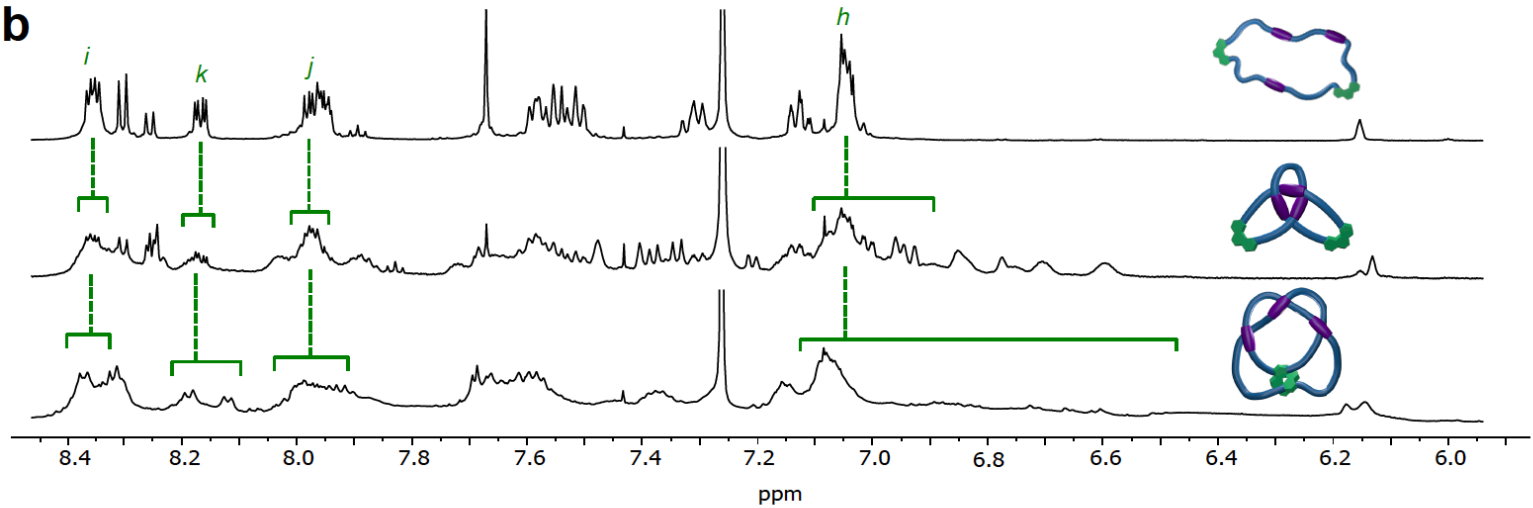

C
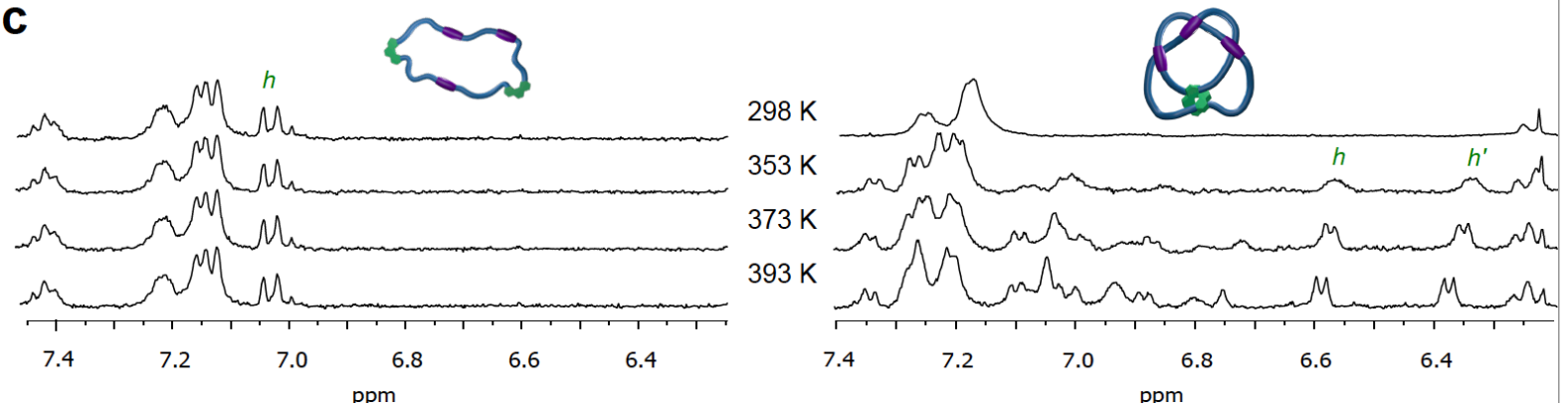

$[\mathrm{M}+\mathrm{Na}]$

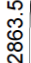

[M+Na]

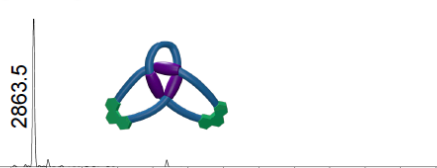

$\left(-3_{1}\right)-1$

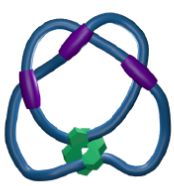

2000

2500

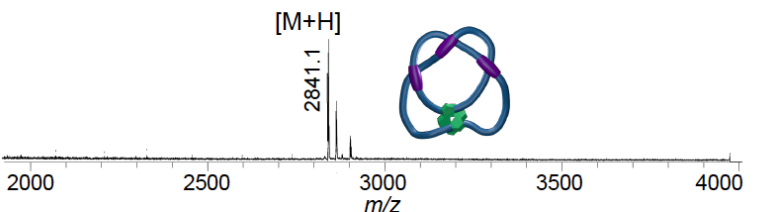

$\mathrm{m} / \mathrm{z}$$$
\text { . }
$$

$\left(+5_{2}\right)-1$ 
Figure 4. Metal-free topoisomer synthesis and characterisation. a) Synthesis of metal-free topoisomers $\left(+5_{2}\right)$ 1, $\left(-3_{1}\right)-1$ and $\left(0_{1}\right)-1$ and their corresponding MALDI-TOF spectra. Reaction conditions: (i) Hoveyda-Grubbs 2 nd Generation catalyst, $\mathrm{CH}_{2} \mathrm{Cl}_{2}, 50^{\circ} \mathrm{C}, 40 \mathrm{~h}, 35 \%$. (ii) $\mathrm{Et}_{4} \mathrm{NF}, \mathrm{MeCN} / \mathrm{CH}_{2} \mathrm{Cl}_{2} 50: 1, \mathrm{RT}, 2 \mathrm{~h}, 57 \%$. (ii) $\left(\mathrm{CH}_{3} \mathrm{CN}\right)_{4} \mathrm{Cu}\left(\mathrm{CF}_{3} \mathrm{SO}_{3}\right), \mathrm{MeCN}, \mathrm{RT}, 10 \mathrm{~min}, 15 \%$. (iii) $\mathrm{KCN}, \mathrm{MeCN} / \mathrm{H}_{2} \mathrm{O} / \mathrm{CH}_{2} \mathrm{Cl}_{2}$ 1:5:5, RT, $16 \mathrm{~h}$; then $\mathrm{Et}{ }_{4} \mathrm{NF}$, $\mathrm{MeCN} / \mathrm{CH}_{2} \mathrm{Cl}_{2} 1: 1.6, \mathrm{RT}, 1 \mathrm{~h}, 66 \%$. b) ${ }^{1} \mathrm{H}$ NMR spectra $\left(600 \mathrm{MHz}, \mathrm{CDCl}_{3}, 325 \mathrm{~K}\right)$ of the topoisomers $\left(0_{1}\right)-1$ (top), ($31)-1$ (middle) and (+52)-1 (bottom). c) Variable temperature $(298-393 \mathrm{~K}){ }^{1} \mathrm{H}$ NMR spectra $(500 \mathrm{MHz}, 1,1,2,2-$ tetrachloroethane- $d_{2}$ ) of unknot $\left(0_{1}\right)-1$ (left) and three-twist knot $\left(+5_{2}\right)-1$ (right). Key ${ }^{1} \mathrm{H}$ signals highlighted, for full assignments see Supplementary information.

\section{Metal-free knot topoisomers}

Once their role of chaperoning the folding and entanglement of the molecular strand is complete, the metal ions can be removed after covalent capture of the topology by RCM. Demetallated knots $\left(-3_{1}\right)-1$ and $\left(+5_{2}\right)-1$ were obtained from treatment of the metal-knot complexes with potassium cyanide $(\mathrm{KCN}$, to remove $\mathrm{Cu}(\mathrm{I}))$ and/or tetraethylammonium fluoride $\left(\mathrm{Et} \mathrm{t}_{4} \mathrm{NF}\right.$, to remove $\left.\mathrm{Lu}(\mathrm{III})\right)$, and the corresponding unknot isomer, $\left(0_{1}\right)-\mathbf{1}$, was produced by macrocyclization of L1 (Fig. 4a). The three topoisomers were confirmed to have the same molecular mass by ESI-MS and matrix-assisted laser desorption ionizationtime of flight (MALDI-TOF) spectrometry, although $\left(0_{1}\right)-1$ and $\left(-3_{1}\right)-1$ formed ions preferentially with $\mathrm{Na}^{+}$ whereas (+52)-1 ionized with a $\mathrm{H}^{+}$(Fig. 4a and Figs. S23-S25). Circular dichroism showed only minor differences between the three topoisomers (Fig. S83), suggesting that in the absence of metal ions none of the knots have a particularly preferred conformation. Rather, the effects of topological chirality are smeared out over the different environments each part of the chain experiences in numerous conformations.

The topoisomers have different diffusion constants in DOSY-NMR measurements (Table S2), with unknot macrocycle $\left(0_{1}\right)-1$ having the smallest effective radius (a result of solvent being able to pass through the cavity of the ring) and the looser knot (31)-1 the largest. The topoisomers have very different room temperature ${ }^{1} \mathrm{H}$ NMR spectra and temperature dependent behaviour (Figs. $4 \mathrm{~b}$ and $4 \mathrm{c}$ ). The ${ }^{1} \mathrm{H}$ NMR spectrum of unknot macrocycle $\left(0_{1}\right)-1$ in $\mathrm{CDCl}_{3}$ is sharp at $298 \mathrm{~K}$, with the minimum number of signals for each type of chemically distinct proton (e.g. $\mathrm{H}_{\mathrm{k}}, \mathrm{H}_{\mathrm{i}}, \mathrm{H}_{\mathrm{h}}$; Fig. $4 \mathrm{~b}$, top). The spectrum in 1,1,2,2tetrachloroethane- $d_{2}$ is essentially invariant between $298 \mathrm{~K}$ and $393 \mathrm{~K}$ (Fig. 4c, left; Fig. S32). In contrast, the ${ }^{1} \mathrm{H}$ NMR spectra of knots $\left(-3_{1}\right)-1$ and $\left(+5_{2}\right)-1$ in $\mathrm{CDCl}_{3}$ are broad at room temperature (Fig. S29) as a consequence of slow reptation ${ }^{45}$ (snake-like motion of the entangled chain through the tight loops and crossings of the knotted backbone). At elevated temperatures sharpening of the resonances occurs for both knots, as reptation becomes faster on the NMR timescale and the signals become timeaveraged. The ${ }^{1} \mathrm{H}$ NMR spectrum of the looser trefoil knot $\left(-3_{1}\right)-1$ is well-resolved at $325 \mathrm{~K}$ in $\mathrm{CDCl}_{3}$ (Fig. 4b, middle), but heating to $393 \mathrm{~K}$ (in 1,1,2,2-tetrachloroethane- $d_{2}$ ) is necessary to obtain sharper features for the more entangled three-twist knot $\left(+5_{2}\right)-1$ (Fig. 4c, right; Fig. S31).

\section{Conclusions}

Metal ions can be used to direct the folding and entanglement of synthetic molecular strands along distinct pathways that result in knotted structures, in a manner reminiscent of the role played by chaperones during protein folding. Different metal ions, and combinations of metal ions, can be used to tie different knots using the same strand. The chirality of one tangle can be used to control the stereochemistry of another, enabling the tying of knots of low or high symmetry. Differently knotted isomers have different properties: for example, in terms of the number of metal ions a closed-loop strand can bind to. Metal ion complexation can also be used to change the position of an entanglement, and consequently the writhe, of the knot. The ability to tie nanoscale strands into different knots, and subsequently change the region and degree of entanglement, opens up new research directions for modifying the function and properties of synthetic molecular structures.

1. Ashley, C. The Ashley Book of Knots (Doubleday, New York, 1994).

2. Lim, N. C. H. \& Jackson, S. E. Molecular knots in biology and chemistry. J. Phys. Condens. Matter 27, 354101 (2015).

3. Tubiana, L., Rosa, A., Fragiacomo, F. \& Micheletti, C. Spontaneous knotting and unknotting of flexible linear polymers: equilibrium and kinetic aspects. Macromolecules 46, 3669-3678 (2013).

4. Amin, S., Khorshid, A., Zeng, L., Zimny, P., \& Reisner, W. A nanofluidic knot factory based on compression of single DNA in nanochannels. Nat. Commun. 9, 1506 (2018).

5. Arai, Y., et al. Tying a molecular knot with optical tweezers. Nature 399 446-448 (1999). 
6. Dietrich-Buchecker, C. O. \& Sauvage, J.-P. A synthetic molecular trefoil knot. Angew. Chem. Int. Ed. 28, 189-192 (1989).

7. Safarowsky, O., Nieger, M., Fröhlich, R. \& Vögtle, F. A molecular knot with twelve amide groups-one-step synthesis, crystal structure, chirality. Angew. Chem. Int. Ed. 39, 1616-1618 (2000).

8. Feigel, M., Ladberg, R., Engels, S., Herbst-Irmer, R. \& Fröhlich, R. A trefoil knot made of amino acids and steroids. Angew. Chem. Int. Ed. 45, 5698-5702 (2006).

9. Adams, H. et al. Knot tied around an octahedral metal centre. Nature 411, 763 (2001).

10. Barran, P. E. et al. Active metal template synthesis of a molecular trefoil knot. Angew. Chem. Int. Ed. 50, 12280-12284 (2011).

11. Ponnuswamy, N., Cougnon, F. B. L., Clough, J. M., Pantos, G. D. \& Sanders, J. K. M. Discovery of an organic trefoil knot. Science 338, 783-785 (2012).

12. Prakasam, T. et al. Simultaneous self-assembly of a [2]catenane, a trefoil knot, and a Solomon link from a simple pair of ligands. Angew. Chem. Int. Ed. 52, 9956-9960 (2013).

13. Ayme, J.-F., et al. Lanthanide template synthesis of a molecular trefoil knot. J. Am. Chem. Soc. 136, 13142-13145 (2014).

14. Cougnon, F. B. L., Caprice, K., Pupier, M., Bauza, A. \& Frontera, A. A strategy to synthesize molecular knots and links using the hydrophobic effect. J. Am. Chem. Soc. 140, 12442-12450 (2018).

15. Segawa, Y., et al. Topological molecular nanocarbons: All-benzene catenane and trefoil knot. Science 365, 272-276 (2019).

16. Hartl, F. U., Bracher, A. \& Hayer-Hartl, M. Molecular chaperones in protein folding and proteostasis. Nature 475, 324-332 (2011).

17. Adams, C. C. The Knot Book: An Elementary Introduction to the Mathematical Theory of Knots (W. H. Freeman, New York, 1994).

18. Eliel, E. L. \& Wilen, S. H. Stereochemistry of Organic Compounds (Wiley, New York, 1994).

19. Gawley, R. E. \& Aubé, J. Principles of Asymmetric Synthesis ( $2^{\text {nd }}$ Edition, Elsevier, New York, 2012).

20. Marenda, M., Orlandini, E. \& Micheletti, C. Discovering privileged topologies of molecular knots with self-assembling models. Nat. Commun. 9, 3051 (2018).

21. Ayme, J.-F. et al. A synthetic molecular pentafoil knot. Nat. Chem. 4, 15-20 (2012).

22. Ponnuswamy, N., Cougnon, F. B. L., Pantos, G. D. \& Sanders, J. K. M. Homochiral and meso figure eight knots and a Solomon link. J. Am. Chem. Soc. 136, 8243-8251 (2014).

23. Danon, J. J. et al. Braiding a molecular knot with eight crossings. Science 355, 159-162 (2017).

24. Zhang, L., et al. Stereoselective synthesis of a composite knot with nine crossings. Nat. Chem. 10, 1083-1088 (2018).

25. Jackson, S. E., Suma, A. \& Micheletti, C. How to fold intricately: using theory and experiments to unravel the properties of knotted proteins. Curr. Opin. Struct. Biol. 42, 6-14 (2017).

26. Flapan, E., He, A. \& Wong, H. Topological descriptions of protein folding. Proc. Natl. Acad. Sci. 116, 9360-9369 (2019).

27. Mallam, A. L. \& Jackson, S. E. Knot formation in newly translated proteins is spontaneous and accelerated by chaperonins. Nat. Chem. Biol. 8, 147-153 (2011).

28. Zhao, Y., Dabrowski-Tumanski, P., Niewieczerzal, S. \& Sulkowska, J. I. The exclusive effects of chaperonin on the behavior of proteins with 52 knot. PLOS Comput. Biol. 14, e1005970 (2018).

29. Virnau, P., Mirny, L. A. \& Kardar, M. Intricate knots in proteins: function and evolution. PLOS Comput. Biol. 2, e122 (2005).

30. Hill, D. J., Mio, M. J., Prince, R. B., Hughes. T. S. \& Moore, J. S. A field guide to foldamers. Chem. Rev. 101, 3893-4012 (2001).

31. Hecht, S. \& Huc, I. (Eds.) Foldamers: Structure, properties, and applications. Wiley-VCH, Weinheim (2007).

32. Maayan, G. \& Albrecht, M. (Eds.) Metallofoldamers: Supramolecular architectures from helicates to biomimetics. Wiley- $\mathrm{VCH}$, Weinheim (2013).

33. Girvin, Z. C., Andrews, M. K., Liu, X. \& Gellman, S. H. Foldamer-templated catalysis of macrocycle formation. Science 366, 1528-1531 (2019).

34. Garber, S. B., Kingsbury, J. S., Gray, B. L. \& Hoveyda, A. H. Efficient and recyclable monomeric and dendritic Ru-based metathesis catalysts. J. Am. Chem. Soc. 122, 8168-8179 (2000). 
35. Forgan, R. S., Sauvage, J.-P. \& Stoddart, J. F. Chemical topology: complex molecular knots, links, and entanglements. Chem. Rev. 111, 5434-5464 (2011).

36. Fielden, S. D. P., Leigh, D. A. \& Woltering, S. L. Molecular knots. Angew. Chem. Int. Ed. 56, 11166-11194 (2017).

37. Conway, J. H. An enumeration of knots and links, and some of their algebraic properties. Computational Problems in Abstract Algebra, (Ed.: Leech, J.), Pergamon Press, Oxford, 329358 (1970).

38. Leigh, D. A., Pirvu, L. \& Schaufelberger, F. Stereoselective synthesis of molecular square and granny knots. J. Am. Chem. Soc. 141, 6054-6059 (2019).

39. Sauvage, J.-P. From chemical topology to molecular machines (Nobel lecture). Angew. Chem. Int. Ed. 56, 11080-11093 (2017).

40. Barry, D. E., Caffrey, D. F. \& Gunnlaugsson, T. Lanthanide-directed synthesis of luminescent self-assembly supramolecular structures and mechanically bonded systems from acyclic coordinating organic ligands. Chem. Soc. Rev. 45, 3244-3274 (2016).

41. Kotova, O., Kitchen, J. A., Lincheneau, C., Peacock, R. D. \& Gunnlaugsson, T. Probing the effects of ligand isomerism in chiral luminescent Lanthanide supramolecular self-assemblies: a Europium "Trinity Sliotar" study. Chem.-Eur. J. 19, 16181-16186 (2013).

42. Gil-Ramírez, G. et al. Tying a molecular overhand knot of single handedness and asymmetric

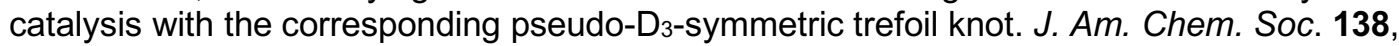
13159-13162 (2016).

43. Rapenne, G., Dietrich-Buchecker, C. \& Sauvage, J.-P. Resolution of a molecular trefoil knot. J. Am. Chem. Soc. 118, 10932-10933 (1996).

44. Shen, T. \& Wolynes, P. G. Statistical mechanics of a cat's cradle. New J. Phys. 8, 273 (2006).

45. de Gennes, P. G. Reptation of a polymer chain in the presence of fixed obstacles. J. Chem. Phys. 55, 572-579 (1971).

\section{Acknowledgements}

We thank the Engineering and Physical Sciences Research Council (EPSRC; EP/P027067/1), the European Research Council (ERC; Advanced Grant no. 786630), the Marie Skłodowska-Curie Actions of the European Union (Individual Postdoctoral Fellowship to F.S., EC 746993) and East China Normal University for funding; the University of Manchester Mass Spectrometry Service Centre for mass spectrometry, the Swedish National Infrastructure for Computing at NSC for computational resources, and networking contributions from the COST Action CA17139, EUTOPIA. We thank Dr. Jean-François Lemonnier and Dr. Stephen Fielden for useful discussions. D.A.L. is a Royal Society Research Professor.

\section{Author contributions}

F.S. and L.P. devised the original concept. D.P.A., L.P., F.S. and J.S. planned and carried out the synthetic work. J.H.S. performed the computational investigations. D.A.L. directed the research. All authors contributed to the analysis of the results and the writing of the manuscript.

\section{Competing Interests statement}

The authors declare no competing interests.

Additional information: Supplementary Information is available for this paper. Correspondence and requests for materials should be addressed to David A. Leigh.

\section{Data availability}

The data that support the findings of this study are available within the paper and its Supplementary Information, or are available from the Mendeley data repository (https://data.mendeley.com/) under doi xxxxxx. 